From what I have had the pleasure of laying before you, the following conclusions occur to me witn more or less of distinctness. That some of them have not been worked out as they should be, is due partly to the limited time at my disposal; partly, it may be, to an inadequate rendering of what presents itself, nevertheless, forcibly to my own mind.

1. Spontaneous generation of plants and animals is a figment which is constantly receding as means of observation extend and inprove.

2. Spontaneous generation of parasitical diseases is a figment.

3. The exanthemata may be a low form of fungoid life.

4. Small-pox, a contagious exanthem, is proved by indisputable negative testimony to be incapable of spontaneous generation.

5. Several other contagious exanthemata cannot originate spontaneously.

6. Enteric fever is a contagious exanthem.

7. Febrile diseases of local origin are not contagious.

8. Experiment* gives strong evidence against the spontaneous origin of enteric fever.

9. Observation, as usually conducted, is a treacherous and insufficient test of the origin of febrile diseases.

St. Peters, Bedford.

\section{CASES IN SURGICAL PRACTICE.}

\section{BY JOHN EWENS, L.R.C.P. LoND., L.R.C.S. EDIN.}

THE following cases occurring recently in my practice, being at least unusual, may, $I$ think, prove of interest.

In Mareh this year I was consulted by a woman, aged sixty-eight, who informed me that she had for the last five zears suffered from uterine hæmorrhage to a greater or less extent. She was very anæmic and depressed. As the administration of astringent remedies failed to give relief, I at once proposed a vaginal examination, expecting to find a polypus. I found nothing abnormal in the vagina, and could at first detect no os nteri, all hough a hard substance, immediately behind the bladder, revealed the presence of the uterus. On the most careful examination, an elevation, with a slight depression in the centre, very similar to, but smaller than, the opening of the urethra, could be made out This I concluded to be the os; and, as no other source of hæmorrhage could be detected, I determined to dilate and examine the uterine cavity. This $I$ did by means of the smallest laminaria tent that I could get; but even this I could not introduce until I had passed an ordinary probe with some difficulty. The tent, being hollow. was placed over the probe, and guided into the canal of the cervix. The patient was ordered to remain in bed for twenty-four hours, so as to retain the tent; but twelve hours after, on rising to pass water, it slipped out. However, the next morning I found that sufficient dilatation had occurred to enable me to pass a larger tent. Next day another difficulty presented itseif. The portion of the tent witain the nterus had expanded in far greater proportion than that in the cervix, and could not possibly be removed with any force which I considered it safe to use. (There was a highlyoffensive sanguineous discharge; so I used an injection of carbolic acid and water, $2 \frac{1}{2}$ per cent., which answered admirably in removing the offensive smell.) I therefore introduced another tent by the side of the one contained in the uterus; and next morning, to my great gratification, I found the os uteri sufficiently dilated to admit of the introduction of one finger, and cleared out from the uterus what I at first thought to be some fibrinous clots. I could detect that the anterior wall was very much thickened, but could not reach to the full extent of the uterine cavity, which was enlarged, and therefore was not sure as to its condition beyond $m y$ reach; but as the patient was very intolerant of pain, very nervous, and somewhat exhausted, I was obliged to defer further examination, intending to repeat the process of dilatation next day. But, at my next risit, I found the patient not only free from pain, but that there had been no bloody discharge since the operation. I therefore concluded that what I considered fibrinous clots were really small warty or polypoid growths. Furthor examination was

* That is, the only kind of experiment which is permissible. objected to. The discharge ceased; but, about two weeks after, a clot of blood escaped with some pain, and with the exception of a trifling sanguineous discharge, following the use of a purgative about a month since, the patient has continued well.

Remarks.-The patient, a widow, never was pregnant-a circumstance explained by the almost impervious condition of the os uteri. She first menstruated at seventeen years of age, and ceased at forty-five. The periods were always attended with pain, and the quantity of discharge was scanty. She always suffered from leucorrhca. The points of interest in connexion with this case appear to be-1st. The long interval between the cessation of the catamenia, at the age of forty-five, and the re-appearance of the sanguineous discharge, as evidence of polypoid growths, at sixty-three. (By the way, I may mention that some years ago I met with a case, in a woman aged seventy, in which the polypus descended into the vagina, and was thence removed by me in a sloughing condition, and hæmorrhage ceased immediately.) 2nd. The nearly obliterated os, and the extreme shortness of the canal of the cervix. Had the cervix been taken up into the body of the uterus by the thickening and consequent expansion of the anterior wall? 3rd. The unintentional and unexpected destructive inflammation set up among the contents of the uterine cavity by the tent introduced on the second day, which, on removal, was found thickly coated with fibrinous deposit. 'The polypi were so thoroughly disorganised that they were easily detached from the uterus, and (as stated above) looked like clots of fibrin. This inflammation was not attended by pain or any serious symptoms. The chief complication in the case arose from the extreme difficulty of reaching the seat of disease, owing to the very contracted state of the vagina and the constricted os uteri.

The second case alluded to is an instance of the comparatively rare accident of fracture of the humerus by muscular action, which oceurred to a boy, aged fourteen years, in attempting to throw a stone. He is quite positive that he did not strike against anything. The fracture is exactly in the middle of the shaft, and apparently is due to violent action of the biceps. It is of the transverse kind, and there has been no tendency to shortening or displacement. Firm. union has already taken place (in sixteen days). The boy is short and stout, with fair bony and rather extra muscular development.

Cerne-Abbas, August 5th, 1870.

\section{PUBLIC VACCINATION.}

Bx THOMAS NEWHAM, M.D., MEDICAL OFFICER 3RD DISTRICT, WINSLOW ENION, BECKS.

Thrreten years of Union work (which, of course, has included a vaccination contract) will be sufficient to prove that $I$ have had some experience of the subject upon which I write; and, although the district I hold is by no means an extensive one, yet I trust the remarks I have to make may not be devoid of interest to the numerous readers of The Lancers.

I propose in the following paper to lay before the profession-first, the method I have pursued in order to secure efficient vaccination; second, the difficulties to be contended against, and how they have been overcome; and lastly, the results.

1. The method I have pursied in order to secure efficient vaccination.-The guardians of this Union have appointed one day in every week for the performance of the operation for the town of Winslow, and one day in every three months for the villages composing the remainder of my district, at the pay-room of the relieving officer. At intervals of three months I obtain from the registrar the names of all children born; and before they are three months old $I$ issue a printed notice to remind the varents when and where the child must be vaccinated. I fiod that the paper given them on the registration of birth frequently finds its way into the fire, or is otherwise lost. B $B$ a little management, I have generally been able to secure fresh $I_{\zeta} \mathrm{mph}$ immediately before visiting my outlying parishes, and thus, if vaccination has 